\title{
Loss of Guidewire
}

Sir,

A male patient suffering from septic shock was referred to the university Intensive Care Unit from another hospital.

Here, a triple-lumen central venous catheter (CVC) was placed, through the right internal jugular vein, using the Seldinger technique. All three ports were aspirated and flushed. The inlying right subclavian $\mathrm{CVC}$ was removed. The entire procedure was described as unproblematic, and a bedside chest X-ray was ordered [Figure 1]. Unfortunately, this was misinterpreted.

As no source for the sepsis could be identified, a computed tomography scan was performed the next day. Surprisingly, hyperdense reflexes were observable in the right heart, most likely indicating a retained guidewire that had inadvertently not been pulled out during CVC placement [Figure 2]. Such

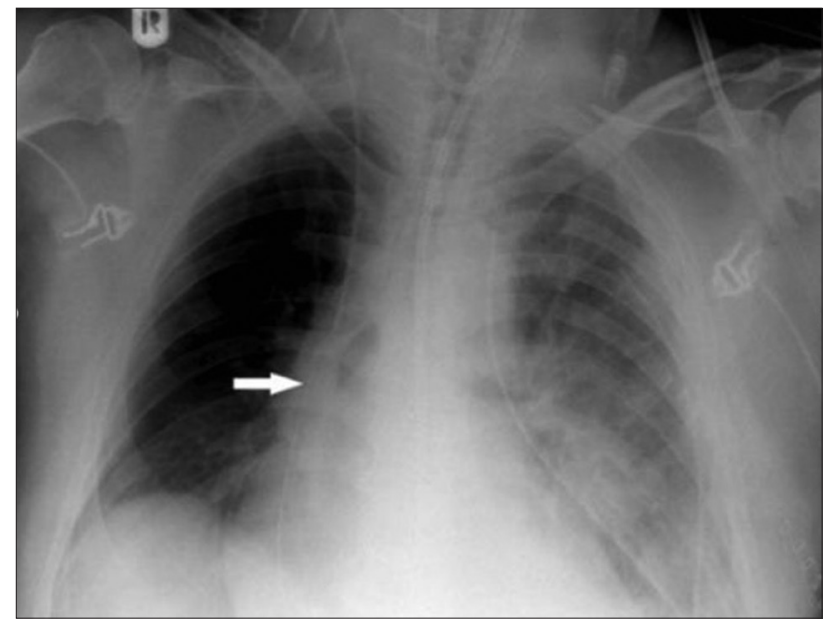

Figure 1: Guidewire (arrow) on bedside chest X-ray, below level of central venous catheter tip

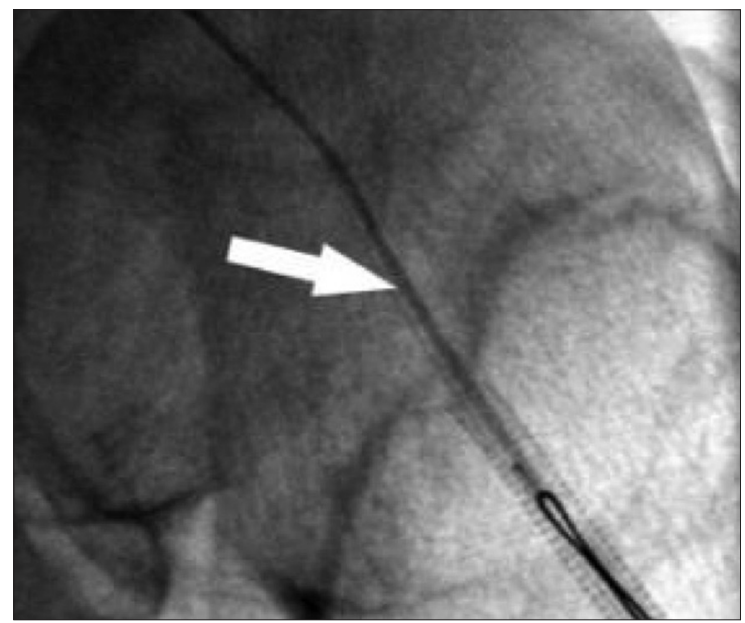

Figure 3: Aligning of guidewire (arrow) inattention-related incidences can result in a variety of potentially life-threatening cardiovascular morbidities.$^{[1]}$ Accordingly, such lost guidewires should be removed as quickly as possible.

Interventional radiology is the recommended method ${ }^{[2]}$ In this case, the guidewire was caught by a gooseneck snare, passed through the femoral vein using radiographic control, and was removed along with the vascular sheath [Figures 3 and 4].

Fortunately, the incidence of lost guidewires is rare; however, in one study, it was calculated to be $0.05 \%{ }^{[3]}$

\section{Take Home Messages}

- Not losing guidewires is of the utmost importance

- While performing central venous access, always hold onto the wire

- If the wire does get lost, it is important to handle the incident appropriately (i.e., identification on chest X-ray and removal by means of interventional radiology).

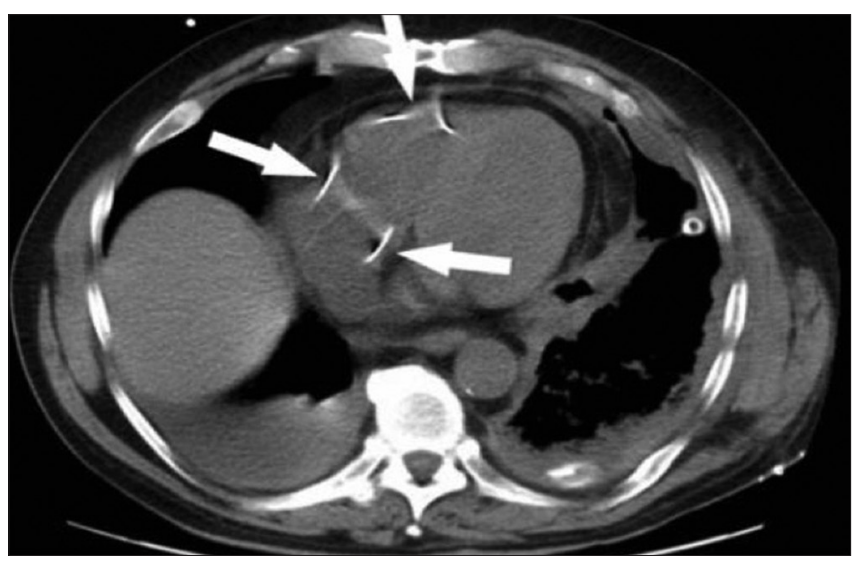

Figure 2: Guidewire in the right heart (arrows indicate reflexes of guidewire)

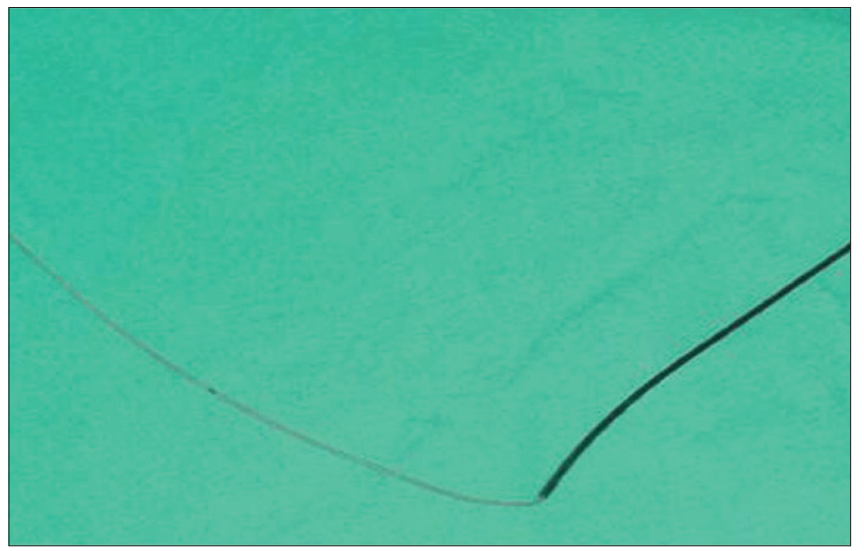

Figure 4: Gooseneck snare with extracted guidewire 
The patient's wife consented to publication of this letter.

\section{Financial support and sponsorship}

Nil.

\section{Conflicts of interest}

There are no conflicts of interest.

Wolfram Schummer ${ }^{1,2}$ ${ }^{1}$ Friedrich Schiller University Jena, Jena, ${ }^{2}$ HELIOS Spital Überlingen, Überlingen, Germany

Address for correspondence: Dr. Wolfram Schummer, HELIOS Spital Überlingen, Härlenweg 2, 88662 Überlingen, Germany. Friedrich Schiller University Jena, Jena, Germany. E-mail: wolfram.schummer@web.de

\section{REFERENCES}

1. Schummer W, Schummer C, Gaser E, Bartunek R. Loss of the guide wire: Mishap or blunder? Br J Anaesth 2002;88:144-6.

2. Egglin TK, Dickey KW, Rosenblatt M, Pollak JS. Retrieval of intravascular foreign bodies: Experience in 32 cases. AJR Am J
Roentgenol 1995;164:1259-64.

3. Omar HR, Sprenker C, Karlnoski R, Mangar D, Miller J, Camporesi EM. The incidence of retained guidewires after central venous catheterization in a tertiary care center. Am J Emerg Med 2013;31:1528-30.

This is an open access journal, and articles are distributed under the terms of the Creative Commons Attribution-NonCommercial-ShareAlike 4.0 License, which allows others to remix, tweak, and build upon the work non-commercially, as long as appropriate credit is given and the new creations are licensed under the identical terms.

\begin{tabular}{|l|l|}
\hline \multicolumn{2}{|c|}{ Access this article online } \\
\hline Quick Response Code: & Website: \\
\hline & www.ijccm.org \\
\hline & \\
\hline
\end{tabular}

How to cite this article: Schummer W. Loss of guidewire. Indian J Crit Care Med 2018;22:561-2.

C 2018 Indian Journal of Critical Care Medicine | Published by Wolters Kluwer - Medknow 